\title{
Phytochemical screening and antibacterial assay of the crude extract and fractions of Ferula oopoda
}

Shazia Iqbal ${ }^{1 *}$, Sultana Arifeen ${ }^{1}$, Ali Akbar ${ }^{2}$, Shaista Zahoor ${ }^{1}$, Saima Maher $^{1}$, Noreen Khan ${ }^{1}$, Hafsa Anwar ${ }^{1}$ and Ashif Sajjad ${ }^{3}$

1. Department of Chemistry, Sardar Bahadur Khan Women's University, Quetta-Pakistan

2. Department of Microbiology, University of Balochistan, Sariab Road, Quetta-Pakistan

3. Institute of Biochemistry, University of Balochistan, Sariab Road, Quetta-Pakistan

*Corresponding author's email:shazia_hej@yahoo.com

Citation

Shazia Iqbal, Sultana Arifeen, Ali Akbar, Shaista Zahoor, Saima Maher, Noreen Khan, Hafsa Anwar and Ashif Sajjad. Phytochemical screening and antibacterial assay of the crude extract and fractions of Ferula oopoda . Pure and Applied Biology. Vol. 8, Issue 1, pp742-749. http://dx.doi.org/10.19045/bspab.2019.80016

\begin{tabular}{|c|c|c|c|}
\hline Received: 30/11/2018 & Revised: 11/01/2019 & Accepted: 16/01/2019 & Online First: 26/01/2019 \\
\hline
\end{tabular}

\section{Abstract}

The principal objective of the current study was to analyse phytochemical constituents and to determine the antimicrobial activity of the crude methanol extract and fractions of chloroform, ethyl acetate and hexane from the whole plant of Ferula oopoda against three bacterial strains Escherichia coli, Salmonella typhi and Staphylococcus aureus. Phytochemical assay confirmed the presence of terpenoid, flavonoids, saponins, tannins, phenolic compounds, carbohydrates, steroids and glycosides. Agar disc diffusion method was used to determine the zone of inhibition of the tested sample for antimicrobial activity. The crude methanolic extract showed activity against $E$. coli ZOI, $30.00 \pm 1.060 \mathrm{~mm}$, for ethyl acetate fractions $50.00 \pm 4.18 \mathrm{~mm}$, for chloroform fraction $27.00 \pm 0.060 \mathrm{~mm}$ and for $\mathrm{n}$-hexane fraction $24.00 \pm 0.353 \mathrm{~mm}$. This observation shows that ethyl acetate fraction possesses great potential against $E$. coli. Inhibition zone for Salmonella typhi was $23.25 \pm 1.050 \mathrm{~mm}$ for ethyl acetate, $14.00 \pm 0.353 \mathrm{~mm}$ for crude methanol extract, $22.00 \pm 1.753 \mathrm{~mm}$ for chloroform fraction and $08.00 \pm 0.352 \mathrm{~mm}$ for $\mathrm{n}$-hexane fraction. This observation shows that $\mathrm{n}$-hexane fraction possesses low potential against Salmonella typhi. Anti-bacterial potential against Staphylococcus aureus strain was maximum in ethyl acetate fraction and showed ZOI, $34.00 \pm 1.767 \mathrm{~mm}$, for chloroform fraction $21.24 \pm 2.636 \mathrm{~mm}$, for crude methanol extract $19.00 \pm 1.060 \mathrm{~mm}$ and for $\mathrm{n}$-hexane fraction $16.00 \pm 1.412 \mathrm{~mm}$ respectively.

Keywords: Antibacterial activity, Ferula oopoda; Phytochemical screening

\section{Introduction}

Infectious diseases are caused by pathogenic microorganisms; some organisms in extreme circumstances can be fatal to the host. According to WHO 80 $\%$ of the world's population uses plant extracts or their active ingredients as folk medicine in several traditional treatments [1]. Plants are considered as a valuable source of therapeutic agents. The research based on the Indo-Pakistan subcontinent it was recorded that plant species were used for medication in Rigveda between 45001600 B.C. There is an extensive knowledge and research based applicability already exist in this region. Some native plants are still widely used in rural areas of Pakistan especially in Balochistan province due to their antimicrobial effect without any logical 
evidence [2]. People use Ferula species for different medicinal purposes such as to get rid of gastric and intestinal worms, lowering blood pressure and controlling diabetes. The methanol extract of Ferula oopoda possess anti-plasmodial activity [3]. The continuous use of plants in folk medicine makes it important to screen the medicinal plants for the discovery of new antimicrobial compounds. The growing concern about the resistant bacterial strains against the antibiotics is of focus point in international communities. Plant constituents having antimicrobial activity can hinder bacterial growth by different mechanisms as compare to that shown by currently used antibiotics. They may also have a significant clinical value in the treatment of resistant microbial strain [4]. Among the plants of Balochistan, the Apiaceae family has a great representation, and several species are used because they contain antimicrobial compounds, antiinflammatory and antifungal agents [5].

The Species Ferula oopoda belong to the family Apiaceae, subfamily Apioideae and genus Ferula.This plant is found in Balochistan region of Pakistan and also found in neighbouring countries of Pakistan such as Iran, Afghanistan and India etc. In Pakistan this plant is mostly cultivated in Northern areas and in Balochistan such as Ziarat, Harboi, Chautair, Chasnak and Sasnamana etc. This medicinal plant possesses amazing significance for the treatment of toothache and gastric disorders. Several biological activities have been described for the species of this genus, such as antibacterial, antioxidant, antifungal, anti-plasmodial and anti-inflammatory activities. These activities are often attributed to the presence of phytochemicals which are bioactive compounds also known as secondary metabolites [6]. Phytochemicals include terpenoids, flavonoids, saponins, tannins, phenolic, carbohydrates, steroids, proteins, glycosides, their essential oils and some non-volatile compounds [6]. These are produced in almost all parts of the plant like leaves, bark, stem, flower, root, seeds and fruits etc [7].

Because of the scarcity of research studies about Ferula oopoda, the aim of this work was to comprehendon the first bioassayguided isolation of the extract and phytochemical investigation of the compounds, to carry out the antimicrobial activity of plant extracts and its fractions against certain pathogenic bacterial strains.

\section{Materials and methods}

Plant collection and sample preparation

The plants were collected from different areas of Harboi (mountainous region of district Kalat, Balochistan, Pakistan). The species for this study was identified as Ferula oopoda. The whole plant was washed with the distilled water and dried naturally i.e. under shade. After completion of drying process, material was ground in a crusher and the powder was stored in sealed plastic bags for further analysis.

\section{Extraction procedure}

Solvent extraction method was used for extracting phytochemicals. Powdered plant sample was soaked in methanol, and then the mixture was subjected to rotary evaporator till the gummy extract was obtained after solvent evaporation. This extract was stored at room temperature for phytochemical and antibacterial analysis.

\section{Fractionation of crude extract of methanol}

Liquid-liquid extraction (LLE) commonly known as solvent extraction and partitioning, is a method where compounds are separated based on their relative solubility in two different immiscible liquids and separate into layers when shaken together. Solvents selected for the present study were ethyl acetate, chloroform and hexane. Selection of these solvent was based on polarity order. First, methanolic extract was dissolved in 200 $\mathrm{ml}$ of distilled water then poured in separating funnel followed by addition of $400 \mathrm{ml}$ ethyl acetate solution. Layer between two different solvents appeared in separation funnel which was then sealed. 
Funnel was shaken vigorously for 20-25 minutes and pressure was released at regular intervals. After 25 minutes two layers were separated, containing fraction in ethyl acetate and n-hexane solvent. The procedure was repeated twice and the obtained fractional extracts were placed in rotatory evaporator at $100 \mathrm{rmp}$ speed to obtain gummy extract material of the fraction. These fractions were stored in refrigerator at $-2^{0} \mathrm{C}$.

The methanolic extract was dissolved in $200 \mathrm{ml}$ of distilled water then poured in separating funnel followed by addition of $400 \mathrm{ml}$ chloroform solution and as mentioned above the same procedure was followed. The procedure was repeated twice. Obtained fractional extracts were placed in rotatory evaporator at $100 \mathrm{rmp}$ speed to obtain gummy extract material of chloroform fraction. Exactly same procedure was followed to obtain n-hexane fraction. Obtained amount of fractional extracts for ethyl acetate was $0.8 \mathrm{~g}$, for chloroform was $0.65 \mathrm{~g}$ and for $\mathrm{n}$-hexane was $0.432 \mathrm{~g}$ respectively. These obtained fractionations were used for phtochemical analysis, TLC, UV and FTIR spectroscopic analysis and antibacterial activity.

\section{Phytochemical analysis}

\section{Terpenoid test (Salkowski test)}

Crude methanol extract $(5 \mathrm{ml})$ was added 2 $\mathrm{ml}$ of chloroform and $3 \mathrm{ml}$ of concentrated sulfuric acid on the test tube's side wall. Reddish brown colour shows the presence of Terpenoid [8].

\section{Flavonoids test}

Mixed methanol crude extract of plant with $3 \mathrm{ml}$ ammonia solution followed by careful addition of sulfuric acid. Yellow colour appeared which indicated the presences of flavonoids in sample [9].

\section{Saponins test (Foam test)}

To the methanolic extract of the plant $(0.5$ $\mathrm{ml}$ ) was added $20 \mathrm{ml}$ of water. The mixture was shaken thoroughly for $15 \mathrm{~min}$. The foam layer appeared which indicated the presence of Saponins [8].

\section{Tannins test}

In methanol crude extracts added 1-2 drop of ferric chloride. Resultant blue colour indicated the positive result [8].

\section{Phenol test}

In crude extract of plant 2-10 drops of ferric chloride solution was added. Greenish colour appeared which show presence of phenol [10].

\section{Steroids test (Liebermann Burchard test)}

In methanol crude extractwas added few drops of acetic anhydride, $2 \mathrm{ml}$ chloroform and $2 \mathrm{ml}$ of sulfuric acid. Presence of Red colour gave positive test [11].

\section{Glycoside test (Keller-Kilian test)}

Acetic acid $(2 \mathrm{ml})$ and sulfuric acid $(2 \mathrm{ml})$ were added in crude extract of plant. Reddish colour formation showed the presence of glycoside in sample [12].

\section{Carbohydrates test (Benedict's reagent)}

Benedict solution was prepared by mixing 17.3 grams of sodium carbonate, sodium citrate and copper sulphate. This reagent was used to confirm presence of carbohydrate. $2 \mathrm{ml}$ of Benedict solution was added in plant extract. The mixture was kept on water bath for a few minutes. Presence of carbohydrate was confirmed by appearance of reddish brown colour [13].

\section{Thin layer chromatography (TLC) preparation of TLC plates}

TLC plates coated with silica gel were used for the analysis. Each plate was of 30 $\mathrm{cm}$ length. A line was marked at $1.5 \mathrm{~cm}$ from bottom of TLC coated plate.

\section{TLC separation}

Mobile phase was prepared by mixing ethyl acetate, chloroform and acetone with ratio 2:2:1. Chromatographic tank was covered and left for some time before analysis so that all tank gets saturated by vapours of mobile phase [14].Capillary tube was used for spotting of plants extracts on TLC plates. The ultra violet (UV) lamp was used to visualize all spots appeared after separation on TLC plates were placed under the UV lamp and circles were drawn to visible zones and followed 
by $R_{f}$ values calculations of different compounds.

\section{UV-VIS spectroscopy}

UV-visible spectrophotometric analysis was carried out at room temperature by using spectrophotometer (Perkin Elmer, USA Model: Lambda 950). The extract and fractions were examined under wavelength from 200-to-800nm and the wavelength selected for research was 300 $\mathrm{nm}$. The crude extract of Ferula oopoda was diluted to 1:10 with distilled water. Distilled water was taken as blank and absorbance of the sample was measured and spectra were obtained. Same procedure was followed for chloroform ethyl acetate and n-hexane fractions [14]. All gummy samples were first dissolved in methanol solvent and then placed in sample cuvettes. Reference cuvette was filled with dilute methanol solvent. Each fraction was tested one by one. In each case absorption was recorded.

\section{Fourier-transform infrared (FTIR) spectroscopy \\ FTIR spectrometer was used for the} identification of the characteristic functional groups in the extract and in the fractions. This spectroscopic technique provides structural information of a molecule from the obtained absorption spectrum. Very small amount of the sample was used for analysis. The spectrum was obtained using Bruker, Germany Vertex 70 infrared spectrometer. The wavelength range used for sample analysis was 4000 to $625 \mathrm{~cm}^{-1}$ [15]. The spectrum was obtained and peak values were recorded

\section{Antibacterial activity}

For antimicrobial activity of an extract or pure compound a variety of laboratory methods can be employed. Broth/agar dilution or disk-diffusion methods are the most commonly used one [16].

\section{Agar well diffusion method}

The antibacterial activity was analysed for crude extracts and fractional extracts of selected medicinal plant. All samples were dissolved in dimethylsulphaoxide (DMSO) solution followed by filtration. The target bacterial species were refreshed in nutrient broth by inoculating them in nutrient broth and incubating at $37^{\circ} \mathrm{C}$ for $24 \mathrm{~h}$. The prepared bacterial culture were spread over the surface of sterile Mueller-Hinton agar plates using sterile cotton swabs. Well (6 $\mathrm{mm})$ were bored in the media and $100 \mu \mathrm{l}$ of each extract was poured aseptically. Plates were observed after 16-24 h incubation at $37{ }^{\circ} \mathrm{C}$. The extracts activities in term of zone of inhibition (ZOI) were analysed visually and recorded in millimetre [17]. DMSO and Doxycycline (DO $30 \mu \mathrm{g}$ ) were used as negative and positive control for this study.

\section{Results and discussion}

Ferula oopoda plant was screened for its phytochemical constituent and antimicrobial activity. Preliminary phytochemical analysis showed that the plant had considerable proportion of important phytochemicals that were detected by qualitative tests. From analysis it was cleared that Ferula oopoda is rich in flavonoids, steroid, glycosides, tannins and phenolic compounds (Table 1). From the literature survey it was found that flavonoids have a variety of biological properties such as antibacterial, antiinflammatory, antiviral, anti-allergic, cytotoxic antitumor properties. It is used in the treatment of neurodegenerative diseases and has vasodilatory action. It is also reported that flavonoids involved in inhibition of platelet aggregation, lipid peroxidation, fragility and capillary permeability, lipoxygenase and cyclooxygenase enzyme activities etc. Flavonoids also inhibit wide range of enzymes like alkaline phosphatases, hydrolases, hyaluronidases, arylsulphatase, cAMP phosphodiesterase, lipase, $\alpha$ glucosidase and kinases [17]. Moreover, saponins exhibit various biological activities like, it gives permeability to the cell membrane, lowers the serum cholesterol levels, it possesses abortifacient properties, it has immunomodulatory property, and it has 
toxic effects on malignant tumor cells and enhances the synergistic toxicity of immunotoxins [18]. Saponins also show antidiabetic property [19]. Tannins are reported to have a cardio-protective, antiinflammatory, anticarcinogenic and antimutagenic properties. Tannins are also involved in treatment of noninsulin dependent diabetes mellitus by enhancing the glucose uptake and inhibiting adipogenesis [20].

Table 1. Qualitative phytochemical contents of Ferula oopoda extract

\begin{tabular}{|c|c|c|c|}
\hline Phytochemicals & Test & Observation & Results \\
\hline Terpenoid & Salkowisk test & Reddish brown colour indicate & Positive (+) \\
\hline Flavonoids & $\begin{array}{c}\text { Ammonia solution +Sulfuric } \\
\text { acid }\end{array}$ & Yellow colour indicates & Positive (+) \\
\hline Starch & Iodine test & No confirmation colour indicate & Negative (-) \\
\hline Saponins & $\begin{array}{c}\text { 1)Foam test and } \\
\text { 2)Spots test }\end{array}$ & $\begin{array}{c}\text { 1) Foam will be formed. } \\
\text { 2) spots form on filtered paper }\end{array}$ & Positive (+) \\
\hline Tannins & Ferric chloride test & Blue colour indicates & Positive (+) \\
\hline Steroids & Chloroform +Sulfuric acid & Red colour indicates & Positive (+) \\
\hline Phenolic & Ferric chloride test & Greenish colour shown & Positive (+) \\
\hline Carbohydrates & Benedict reagent test & bricks red colour indicates & Positive (+) \\
\hline Glycosides & Acetate acid +Sulfuric acid & Brown colour indicate & Positive (+) \\
\hline
\end{tabular}

\section{TLC profile}

The retention factors $\left(\mathrm{R}_{\mathrm{f}}\right)$ of crude methanol extract, ethyl acetate and nhexane and chloroform fractions in solvents system are shown in (Table 2). The chromatogram revealed 3, 3, 2 and 2 spots for crude methanol, ethyl acetate, chloroform and n-hexane fractions respectively.TLC profiling of crude methanol extract, ethyl acetate and nhexaneand chloroform fractions was very impressive which directs towards the presence of a variety of phytochemical. $R_{f}$ values of different phytochemicals differ in different solvent system. These variable $\mathrm{R}_{\mathrm{f}}$ values provide important information about the polarity and selection of solvent system for chromatographic separation of pure compounds in column chromatography. Mixture of solvents of different polarity in variableratio can be used for separating pure compound of plant extract. Therefore, $R_{f}$ values of compounds in variable solvent system can be used for selecting appropriate solvent system for plant extracts [21].Secondary metabolites of plants can be identified accurately by TLC method. The obtained different $R_{f}$ values in this presented study showeddifferent profile in a single extract.The results also gave an idea about the polarity which helps during the selection of suitable solvent system for further separation of compound from the plant extracts.

Table 2. Rf values of TLC solvent system for extract and fractions of Ferula oopoda

\begin{tabular}{|c|c|c|c|c|}
\hline Interface & Mobile phase & Ratio & No of spot detected & $\mathbf{R}_{\mathbf{f}}$ Values \\
\hline $\begin{array}{c}\text { Crude methanol } \\
\text { extract }\end{array}$ & Ethyl acetate: chloroform: acetone & $2: 2: 1$ & 03 & 0.061 \\
& & & 0.723 \\
$\begin{array}{c}\text { Ethyl acetate } \\
\text { fraction }\end{array}$ & Ethyl acetate: chloroform: acetone & $2: 8.5: 1$ & 02 & 0.786 \\
\hline $\begin{array}{c}\text { Chloroform } \\
\text { fraction }\end{array}$ & Acetone: chloroform: ethyl & $2: 2: 1$ & 03 & 0.723 \\
acetate & & & 0.531 \\
\hline $\begin{array}{c}\text { n-Hexane } \\
\text { fraction }\end{array}$ & Ethyl acetate: chloroform: acetone & $2: 2: 1$ & 02 & 0.89 \\
\end{tabular}


UV-VIS Analysis

The UV-VIS analysis was carried out to study the phytochemicals present in methanolic extract and respective fractions of Ferula oopoda. Theanalysis was performed to confirm the compounds having $\sigma$ and $\pi$-bonds, unshared electrons, aromatic rings and chromophores. Absorption bands of Ferula oopoda plant extract are showed in (Table 3). The UV profile showed the bands at 278, 279, 320,
$327,328, \quad 287,416,600$ and 663 respectively. Appearance of absorption bands in the wavelength range from 200 to $400 \mathrm{~nm}$ indicates the presence of unsaturation and heteroatoms like $\mathrm{N}, \mathrm{S}$ and $\mathrm{O}$ [22]. The spectrums for Ferula oopoda extract and fractions show six peaks at positions $327 \mathrm{~nm}, 278 \mathrm{~nm}, 287 \mathrm{~nm}, 320 \mathrm{~nm}$ this sanctions the presence of organic chromophores within the Ferula oopoda.

Table 3. UV/VIS Interpretation data of extract and fractions of Ferula oopoda

\begin{tabular}{|c|c|c|}
\hline Interface & Region of band (nm) & Interpretation \\
\hline \multirow{2}{*}{ Crude methanol extract } & 278 & Benzoyl band of flavonoids \\
\cline { 2 - 3 } & 327 & Cinnamoyl band of flavonoids \\
\hline \multirow{2}{*}{ Ethyl acetate } & 328 & Cinnamoyl band of flavonoids \\
\cline { 2 - 3 } & 287 & Benzoyl band of flavonoids \\
\hline \multirow{3}{*}{ Chloroform } & 600,663 & Chlorophyll a and b carotenoids \\
\cline { 2 - 3 } & 416 & Chlorophyll a and b carotenoids \\
\cline { 2 - 3 } & 320 & Cinnamoyl bands of flavonoids \\
\cline { 2 - 3 } & 279 & Benzoyl band of flavonoids \\
\hline n. hexane & 235 & Flavonoids band \\
\hline
\end{tabular}

\section{FTIR analysis}

The FTIR analysis was done for the identification of functional group of the constituent components on the basis of various peaks obtained in the IR region. The FTIR spectrum of the Ferula oopoda plant extract is shown in (Table 4). IR peak at $3200 \mathrm{~cm}^{-1}$ confirms the presence
$\mathrm{OH}$ groups in the extract. Peak at $2913 \mathrm{~cm}^{-}$ 1 is because of symmetric stretching of saturated (sp3) C and IR peak at1601.00$1407.80 \mathrm{~cm}^{-1}$ is due to $\mathrm{C}=\mathrm{C}$ stretching associated with the aromatic skeletal mode of the extracts. A notable band at1234.86$1011.97 \mathrm{~cm}^{-1}$ can be due to C-O stretching [21].

Table 4. FTIR spectrum of sample the Ferula oopoda extract

\begin{tabular}{|c|c|c|}
\hline Wave numbers $\mathbf{~ m}^{-1}$ & Type of bonds & Interpretation \\
\hline $3200 \mathbf{c m}^{-1}$ & O-H & Alcohol, or phenolic groups \\
\hline $2913 \mathbf{c m}^{-1}$ & $\mathrm{C}-\mathrm{H}$, & Alkyl groups like methyl, ethyl groups \\
\hline $1741 \mathbf{~ m}^{-1}$ & $\mathrm{C}=\mathrm{O}$ & Carbonyl compound \\
\hline $1601,00-1407.80 \mathbf{c m}^{-1}$ & $\mathrm{C}=\mathrm{C}$ & Aromatic compounds \\
\hline $1234,86-1011.97 \mathbf{c m}^{-1}$ & $\mathrm{C}=\mathrm{O}$ & Alcohol, phenolic, ether, ester, glycosides linkages \\
\hline
\end{tabular}

\section{Antibacterial assay}

The antibacterial activity showed positive response in all fractions and in crude methanol extract (Table 5). The analysis for E.coli strains showed ZOI of $29 \mathrm{~mm}$ in crude methanol extract, $50 \mathrm{~mm}$ in ethyl acetate fractions, and $27 \mathrm{~mm}$ in chloroform fraction and $24 \mathrm{~mm}$ in $\mathrm{n}$-hexane. These observations showed least potential of n- hexane fraction with significant potential Salmonella analysis with crude extract, ethyl acetate fraction, chloroform fraction and n-hexane fraction showed respectively ZOI $14 \mathrm{~mm}, 23 \mathrm{~mm}, 22 \mathrm{~mm}$ and $0.8 \mathrm{~mm}$. significant result was showed by ethyl acetate fraction. Staphylococcus aureus showed maximum inhibition zones found in ethyl acetate fraction with value $34 \mathrm{~mm}$. 
The chloroform fraction, crude methanolic extract and n-hexane showed ZOI as 21 $\mathrm{mm}, 19 \mathrm{~mm}$ and $16 \mathrm{~mm}$ respectively. These observations reveal significant potential of plant to act as antibacterial agent. Thus, plant active component may be useful in synthesis of effective drugs to treat bacterial infection.

Table 5. Inhibition zones of Ferula oopoda methanol extract and different fractions against pathogenic bacteria.

\begin{tabular}{|c|c|c|c|c|}
\hline \multirow{2}{*}{ Bacterial strains } & \multicolumn{4}{|c|}{ Mean zones of inhibition (mm) } \\
\cline { 2 - 5 } & $\begin{array}{c}\text { Crude methanol } \\
\text { extracts }\end{array}$ & $\begin{array}{c}\text { Chloroform } \\
\text { fraction }\end{array}$ & $\begin{array}{c}\text { Ethyl acetate } \\
\text { fraction }\end{array}$ & $\begin{array}{c}\text { n-hexane } \\
\text { Fraction }\end{array}$ \\
\hline E. coli & $30.00 \pm 1.060$ & $27.00 \pm 0.060$ & $50.00 \pm 4.182$ & $24.00 \pm 0.353$ \\
\hline S. typhi & $14.00 \pm 0.353$ & $22.00 \pm 1.753$ & $23.25 \pm 1.050$ & $08.00 \pm 0.352$ \\
\hline S. aureus & $19.00 \pm 1.060$ & $21.24 \pm 2.636$ & $34.00 \pm 1.767$ & $16.00 \pm 1.412$ \\
\hline
\end{tabular}

Means \pm SD

\section{Conclusion}

This study gave an insight and information for the determination of chemical composition of Ferula oopoda using different biochemical tests and results were confirmed by TLC, UV-VIS and FTIR techniques. In the present study flavonoids, steroid, glycosides, tannins and phenolic compounds were identified from methanolic plant extract and its different fractions. The presence of phytochemical constituents in Ferula oopoda gives credible evidence to its use by the human being. Novel drugs can be prepared by isolating these specific compounds. It could be concluded that Ferula oopoda contains various bioactive compounds which makes it an important pharmaceutical plant. However, further studies are needed to be undertaken to determinecomprehensively its toxicity profile, bioactivity, effect on the ecosystem and agricultural products.

\section{Authors' contributions}

Conceived and designed the experiments: S Iqbal, S Arifeen, S Zahoor \& S Maher, Performed the experiments: $S$ Iqbal, $S$ Arifeen \& A Akbar, Analyzed the data: S Iqbal, S Arifeen, S Zahoor, S Maher, A Sajjad \& A Akbar, Contributed materials/ analysis/ tools: $\mathrm{S}$ Iqbal, $\mathrm{S}$ Arifeen, $\mathrm{S}$ Zahoor \& $S$ Maher, Wrote the paper: $S$ Iqbal, S Arifeen, S Zahoor, S Maher \& A Sajjad.

\section{References}

1. WHO (2013). WHO traditional medicine strategy 2014-2023. World Health Organization.

2. Aziz-UL-Ikram NBZ, Shinwari ZK \& Qaiser M (2015). Ethnomedicinal review of folklore medicinal plants belonging to family Apiaceae of Pakistan. Pak. J Bot 47(3): 1007-1014.

3. Akhgar MR, Moradalizadeh M, Faghihi-Zarandi A \& Rajaei P (2011). Chemical Composition of the Essential Oils of Ferula oopoda (Boiss. \&Buhse) Boiss. And Ferula badghysi (Korovin.) from Iran. $J$ of Essential Oil Bearing Plants 14(3): 297-301.

4. Eloff JN (1998). Which extractant should be used for the screening and isolation of antimicrobial components from plants. $J$ of Ethnopharmacol 60(1): 1-8.

5. Chanda S \& Rakholiya K (2011). Combination therapy: Synergism between natural plant extracts and antibiotics against infectious diseases. Science against microbial pathogens: communicating current research and technological advance, A. MéndezVilas (Ed.) 520-529.

6. Da Silva Sa FA, de Paula JAM, dos Santos PA, de Almeida Ribeiro Oliveira L, de Almeida Ribeiro Oliveira G, Liao LM, \& do Rosario Rodrigues Silva M (2017). Phytochemical Analysis and 
Antimicrobial Activity of Myrciatomentosa (Aubl.) DC. Leaves. Mol 22(7): 1100.

7. Bansode TS \& Salalkar BK (2015). Phytochemical analysis of some selected Indian medicinal plants. Int $J$ Pharm Bio Sci 6(1): 550-556.

8. Savithramma N, Rao ML \& Suhrulatha D (2011). Screening of medicinal plants for secondary metabolites. Middle-East J of Sci Res 8(3): 579-584.

9. Soni A \& Sosa S (2013). Phytochemical analysis and free radical scavenging potential of herbal and medicinal plant extracts. $J$ of Pharmaco and Phytochem 2(4): 2229.

10. Tamilselvi N, Krishnamoorthy $P$, Dhamotharan R, Arumugam $\mathrm{P} \&$ Sagadevan E (2012). Analysis of total phenols, total tannins and screening of phytocomponents in Indigofera aspalathoides (Shivanar Vembu) Vahl EX DC. $J$ of Chem and Pharm Res 4(6): 3259-3262.

11. Cook RP (1961). Reactions of steroids with acetic anhydride and Sulfuric acid (the Liebermann-Burchard test). Analyst 86(1023): 373-381.

12. Sheel R, Nisha K \& Kumar J (2014). Preliminary phytochemical screening of methanolic extract of Clerodendron infortunatum. IOSR J Appl Chem 7(1): 10-13.

13. Teja M, Ramya B, Reddy SM, Sudha GJ, Janaki B, Rama S, \& Kumar SAR (2016). Preliminary phytochemical evaluation of Caesalpinia sappan saraca indica. Int J Res Pharm Chem 6(1).
14. Benedict SR (1909). A reagent for the detection of reducing sugars. $J$ of Biol Chem 5(5): 485-487.

15. Jayashree D (2013). Pytochemicals analysis and TLC fingerprinting of methanolic extracts of three medicinal plants. Int Res J Pharm 4(6): 1231236.

16. Jain PK, Soni A, Jain P \& Bhawsar J (2016). Phytochemical analysis of Menthaspicata plant extract using UV-VIS, FTIR and GC/MS technique. J Chem Pharm Res 8(2): 1-6.

17. Agarwal AD (2011). Pharmacological Activities of Flavonoids: A review. Inter J of Pharm Sci and Nanotechnol 4(2): 1394-1399.

18. Thakur M, Melzig MF, Fuchs $\mathrm{H} \&$ Weng A (2011). Chemistry and pharmacology of saponins: special focus on cytotoxic properties. Botanics: Targets and Therapy 1: 1929.

19. Zheng T, Shu G, Yang Z, Mo S, Zhao $Y$ \& Mei Z (2012). Antidiabetic effect of total saponins from Entadaphaseoloides (L.) Merr. in type 2 diabetic rats. $J$ of Ethnopharmacol 139(3): 814-821.

20. Kumari M, \& Jain S (2012) Tannins: An Antinutrient with Positive Effect to Manage Diabetes. Res $J$ of Recent Sci 1(12): 1-8

21. Gujjeti RP, \& Mamidala E (2013). Phytochemical analysis and TLC profile of Madhucaindica inner bark plant extract. Inter $J$ of Sci \& Engin Res 4(10): 1507-1510.

22. Jain PK, Soni A, Jain P \& Bhawsar J (2016). J of Chem and Pharm Res 8(2): 1-6. 